\title{
Additive Manufactured Nanocomposites for Bone Tissue Engineering Applications: an Overview
}

\author{
Lya Piaia ${ }^{a, c} * \mathbb{1}$, Gean Vitor Salmoria ${ }^{a, b} \mathbb{1}$, , Dachamir Hotza ${ }^{a, c} \mathbb{1}$ \\ ${ }^{a}$ Universidade Federal de Santa Catarina (UFSC), Departamento de Engenharia Mecânica (EMC), \\ Laboratório de Inovação em Fabricação e Moldagem Aditiva (NIMMA), 88040-900 Florianópolis, SC, Brasil \\ ${ }^{b}$ Universidade Federal de Santa Catarina (UFSC), Hospital Universitário (HU), Laboratório de \\ Engenharia Biomecânica (LEBm), 88040-900 Florianópolis, SC, Brasil \\ 'Universidade Federal de Santa Catarina (UFSC), Departamento de Engenharia Química (EQA), \\ Laboratório Interdisciplinar de Desenvolvimento de Nanoestruturas (LINDEN), 88040-900 \\ Florianópolis, SC, Brasil
}

Received: August 28, 2019; Revised: January 20, 2020; Accepted: January 29, 2020

\begin{abstract}
Tissue Engineering aims to repair, regenerate or restore damaged tissues. Structures known as scaffolds can be manufactured in different ways and with various materials such as synthetic and natural polymers as well as inorganic materials. Additive Manufacturing (AM) has been used to produce porous scaffolds. Particularly, Selective Laser Sintering (SLS) produces materials and composites through a selective solidification of a variety of fine powders. AM-made biomaterials may be suitable for different affected or injured parts by stimulating the biological system around the implant. The present work aims to review relevant concepts concerning the nanostructure for regeneration of the bone tissue when in contact with the native tissue, as well as the suitable techniques and materials to fabricate it.
\end{abstract}

Keywords: Tissue Engineering; Scaffolds; Selective Laser Sintering.

\section{Introduction}

Tissue engineering is based on the development of scaffolds that permit regeneration of the tissue with defect. The development of scaffolds allows the regeneration of damaged bone tissue, which usually can be derived from a natural bone defect or removed from the tumors and/or fractures ${ }^{1}$. Therefore, there is a great call for materials and procedures for bone regeneration, such as spontaneous regeneration and/or autologous/allogeneic transplantation. A variety of materials and techniques have been investigated over the last two decades to produce these scaffolds ${ }^{2-5}$.

Scaffolds must have a structure that try to mimic the extracellular matrix (ECM) found in native tissue ${ }^{3}$. These structures should facilitate the migration, proliferation and adhesion of cells, thus playing the role of a "real" native tissue. Scaffolds must also be biocompatible, have mechanical strength, controlled porosity, and interconnected pore network, among other characteristics that differ from tissue to tissue ${ }^{6}$.

In search of the improvement of these characteristics of the scaffolds in recent years, alternatives are been studied with greater intensity. In this context arise the techniques of Additive Manufacturing (AM), which produce scaffolds with controlled geometry and $100 \%$ interconnectivity through the progressive application of layers of material by combination of CAD software with the use of inorganic and polymeric materials?

Still in the perspective of improved scaffolds, some substances can be incorporated in their structure, or deposited as a coating in the production process, also in order to increase mechanical strength, flexibility, porosity and cell culture ${ }^{8,9}$.

*e-mail: lyapiaia@hotmail.com.
In this overview, a search procedure was performed using Scopus, NCBI PubMed and Web of Science platforms, with the following combination of keywords: "bone tissue" and nanomaterials; "features of a scaffolds" and "biomaterials"; "additive manufacturing techniques" and "scaffolds"; "tissue engineering" and "nanomaterials"; "materials for production of scaffolds"; "biocomposites" and "bone regeneration"; "bioceramics" and "scaffolds"; "polymers" and "ceramic scaffolds"; "bone morphogenetic". These keywords were searched amongst article title, abstract and keywords. Since the objective of this research was to identify recent nanocomposites for bone tissue, articles published 2005 until 2019 were searched. Open access and CAPES-consortium available publications were downloaded and analyzed. By selecting only research articles and excluding duplicates, we found a total of 200 articles. The main concepts and findings are summarized in the following sections.

\section{Bone Tissue Engineering}

Bone tissue is chemically composed of two parts: an organic part and an inorganic part. The organic part consists basically of cells (osteoclasts and osteoblasts) and collagen fibers; the inorganic part is formed by calcium phosphates such as hydroxyapatite, equivalent to $70 \%$ of the total bone mass ${ }^{10}$.

Structurally, the bone tissue is composed of two parts: one part corresponding to the cortical bone and the other part to the trabecular bone (Figure 1). The most compact bone that is involving bone marrow and attaches to mechanical strength to bone is known as the cortical bone, which can reach $30 \%$ porosity volume and with pore sizes of $10-20 \mu \mathrm{m}$. The more spongy bone, due to its higher porosity, which 


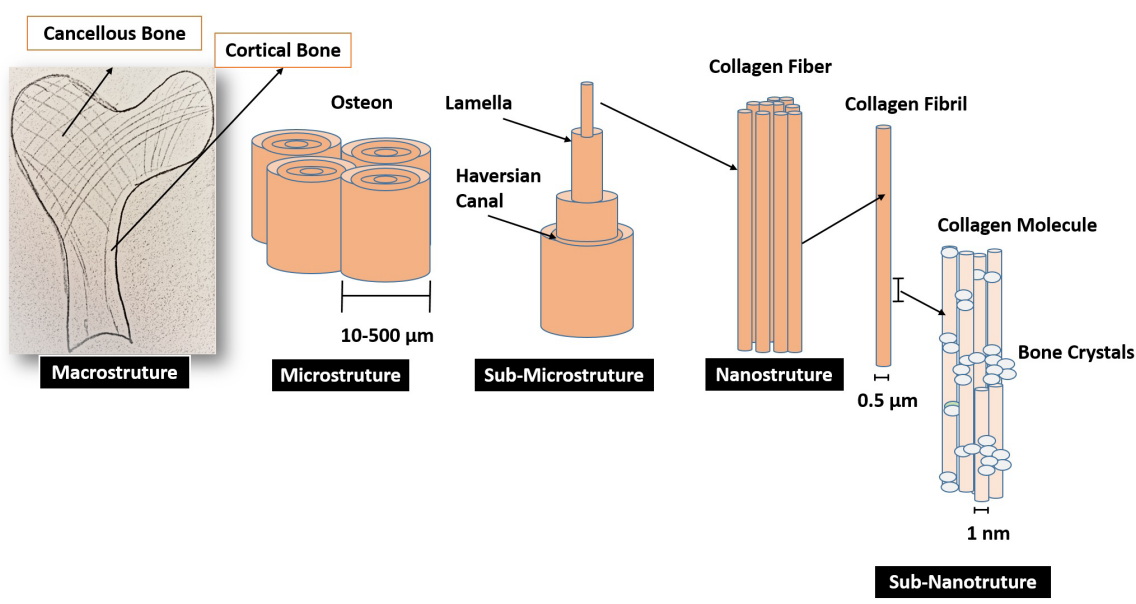

Figure 1. Anatomy of bone. (Adapted of Bao C, Teo E, Chong M., 2013; Clarke B, 2008).

Table 1. Properties of cortical and trabecular bones.

\begin{tabular}{lcccccc}
\hline \multirow{2}{*}{ Type of bone } & \multirow{2}{*}{ Porosity (\%) } & \multirow{2}{*}{$\begin{array}{c}\text { Apparent } \\
\text { density }\left(\mathbf{g} \cdot \mathbf{c m}^{-3}\right)\end{array}$} & $\begin{array}{c}\text { Modulus of } \\
\text { elasticity (GPa) }\end{array}$ & \multicolumn{3}{c}{ Mechanical Strength (MPa) } \\
\cline { 5 - 7 } & & $1.8-2.0$ & $7-30$ & $100-230$ & $78-150$ & $50-150$ \\
\hline Cortical bone & $5-30$ & $0.1-0.9$ & $0.05-0.5$ & $2-12$ & - & Frexion \\
\hline Trabecular bone & $30-90$ & & &
\end{tabular}

Font: Adapted of Bao; Teo; Chong, 2013; Kokubo; Kim; Kawashita, 2003.

can vary from $30-90 \%$ with pore sizes of $100 \mu \mathrm{m}$, is known as the trabecular bone $\mathrm{i}^{10-12}$. Some common properties of the cortical and trabecular bones are presented in Table 1.

\subsection{Regeneration of bone tissue}

The most common bone fracture healing is indirect or secondary consolidation. This bone healing consists of endochondral and intramembranous, which is characterized by the formation of intermediate callus before the formation of the bone callus ${ }^{13}$.

Bone regeneration is composed of four steps. The first phase is the immediate inflammatory response, leading to signaling to stem cells, which will differentiate into chondrocytes that will produce cartilage and osteoblasts, forming a new bone. After the already formed cartilaginous matrix, it will be mineralized, and then it will be resorbed forming the bone. This formation generates the primary bone, which undergoes a remodeling of the preformed bone callus, occurring a second resorption, which restores the anatomical structure ${ }^{13}$.

From the beginning of the process of regeneration of injured bone tissue, tumor necrosis factors (TNF- $\alpha)$, interleukins, as well as factors that recruit inflammatory cells ${ }^{13}$, as well as stimulating the synthesis of Extracellular Matrix (ECM) and angiogenesis at the lesion site ${ }^{14}$. During injury repair, morphological bone proteins (BMPs) are produced, which function independently or in collaboration with other cells. The BMPs stimulate a cascade of events that will promote the formation of cartilage and bone ${ }^{14}$.

Direct consolidation is not a natural process of regeneration that commonly occurs. Direct regeneration of the injured site will not result in periosteal or endosteal callus formation. This consolidation takes place with the reduction of the interfragmentary tension, by the action of an internal fixation surgery. Later it initiates the process of regeneration, and it may take years for the formation of the new bone to occur completely ${ }^{14}$.

In the perspective of efficient bone regeneration, in the last years biomaterials are being investigated. Their composition normally comprises an osteocondutor ceramic material, conjugated with a biodegradable, bioactive polymer. Current research is focused in adding proteins to those materials as well as activating the surface thorough a surface treatment, with the intention of developing a material capable of being used as a permanent replacement ${ }^{2,3,15-18}$.

BMPs are pleiotropic molecules that are involved in chemotaxis, mitosis and differentiation of mesenchymal cells in bone tissue, but these proteins need a carrier for effective osteoconduction. BMPs belong to the superfamily of the Tumor Growth Factor $\beta$ (TGF- $\beta$ ), and were discovered by Urist (1965), who verified that bone arrays implanted at ectopic sites promoted bone formation ${ }^{19,20}$.

The activity of the BMPs involves a complex system of signals to the coupling of enzymes and of factors in the repair ways ${ }^{21}$. Since the formation of bone tissue cannot occur simply by injecting an aqueous solution of recombinant human BMP-2 (rhBMP-2) into the target site, as this would be rapidly eliminated from the site of application ${ }^{22}$. In this way, a biomaterial with osteoconductive and biodegradable characteristics can serve as a carrier for the BMPs in the host tissue.

BMP-2 can promote significant bone cell differentiation, mesenchymal cells into chondrocytes and osteoblasts, and induces precursor cells of osteoblast to differentiate into osteocytes, as well the formation of the blood vessels ${ }^{23}$. During the fracture healing, bone formation and cartilage formation also can be promoted by BMP-2 to induce bone formation by stimulating osteoblast differentiation and chondrogenic differentiation separately ${ }^{24,25}$. 


\subsection{Features of a scaffold}

Scaffolds must modulate the healing process by providing a mechanical support and stimulate the onset of cell colonization, by action of the physiological and biological process forming a new tissue ${ }^{3}$, promoting regeneration without training necrosis or scarring at the site of implantation ${ }^{3}$.

Scaffolds depend on some important requirements when it comes to materials for their development. Firstly, biocompatibility of the substrate materials is indispensable. The material must not educe an unresolved inflammatory response nor demonstrate immunogenicity or cytotoxicity ${ }^{26-28}$. In addition, the mechanical properties of the scaffold must be sufficient to prevent structural failure during handling and during the patient's normal activities. An important requirement in scaffolds for bones is porosity, which directs the cells in their physical structure and serves as support for vascularization. A typical porosity of $90 \%$ as well as a pore diameter of at least $100 \mu \mathrm{m}$ is known to be required for cell penetration and a proper vascularization of the ingrown tissue $^{18,28}$ (Figure 2).

Several materials in the development of scaffolds have been explored for the regeneration of tissues, based on physical, chemical and biological properties that are most suitable to stimulate the production of new tissues. Natural and synthetic polymers, as well as inorganic materials are major sources of raw materials for scaffolds in the regeneration of tissues, such as bone, skin, ligaments, etc ${ }^{3,29}$.

Natural polymers such as chitosan, chitin, collagen, glycosaminoglycans, gelatin, elastin, and bacterial cellulose have been used in various applications in tissue engineering ${ }^{30-34}$. Some of these polymers are present in the ECM of many native tissues and enhances the adhesion and the functionality of the cells ${ }^{3}$.

Bioactive inorganic materials, such as hydroxyapatite (HAp), and tricalcium phosphate (TCP), are biocompatible and osteoconductive. These properties are due to the chemical composition of these materials that are close to the inorganic mineral phase found in the bone tissue ${ }^{15,16}$.

In recent years, methodologies for producing three-dimensional (3D) porous structures are being investigated. In this case, it is possible to use natural sources (plants and bacteria) and synthetic polymers combined. These 3D structures intended to simulate the environment the of ECM of the native tissue, facilitating the regeneration of injured tissues ${ }^{35}$. Thus, scaffolds need to be produced with the aim to remedy the biological requirements seeking to mimic the cellular microenvironment of the ECM and technical requirements of implementation and low cost $\mathrm{t}^{36}$.

Scaffolds must have basic features to play its role literally. The main characteristics of a scaffold include: biocompatibility, bioactivity, biodegradability, biorreabsorption, mechanical compatibility, porosity, and non-toxic nature ${ }^{6,37}$.

These characteristics need to be connected with the aim desired of this scaffold, because scaffolds have specific properties depending on the application. For example, if the goal is bone tissue regeneration, a scaffold must be biocompatible and have similar mechanical properties to those of a natural bone ${ }^{37}$. For comparison, cortical and trabecular bone compressive strength are 100-230 and 2-12 MPa and for bending strength are 50-150 and 10-20 MPa, respectively ${ }^{38}$. Furthermore, the scaffold must have an environment that promotes the growth, proliferation and differentiation of cells. This environment must have a $3 \mathrm{D}$ structure with porosity $>40-60 \%$ and an interconnected network for cellular growth, which favors the rapid diffusion of nutrients and metabolic waste as well as cell migration ${ }^{6,39}$. The implants of this material take between 6 and 15 weeks to be partially bioreabsorbed, time that depends mainly on the porosity of the implant ${ }^{40}$.

Many scaffolds are being developed for different purposes, which have different chemical compositions and different physical and chemical properties, being produced by distinct methods. In the search of controlled structure and porosity, the method of $3 \mathrm{D}$ printing (3DP) stands out, allowing to produce scaffolds with different components and controlled geometry, interconnectivity, and disposition of layers with different components ${ }^{37}$.

\section{Additive Manufacturing Techniques for Scaffolds}

Additive Manufacturing (AM) is a technique that produces uniform, complex shaped 3D scaffolds, promoting an improvement in the structural characteristics, as controlled connectivity and porosity. Furthermore, AM can produce scaffolds from customized images, obtained by computer tomography or magnetic resonance, together with CAD techniques ${ }^{41,42}$.

Many processes of AM can be used for production of scaffolds aimed to prostheses. Typically, five processes are

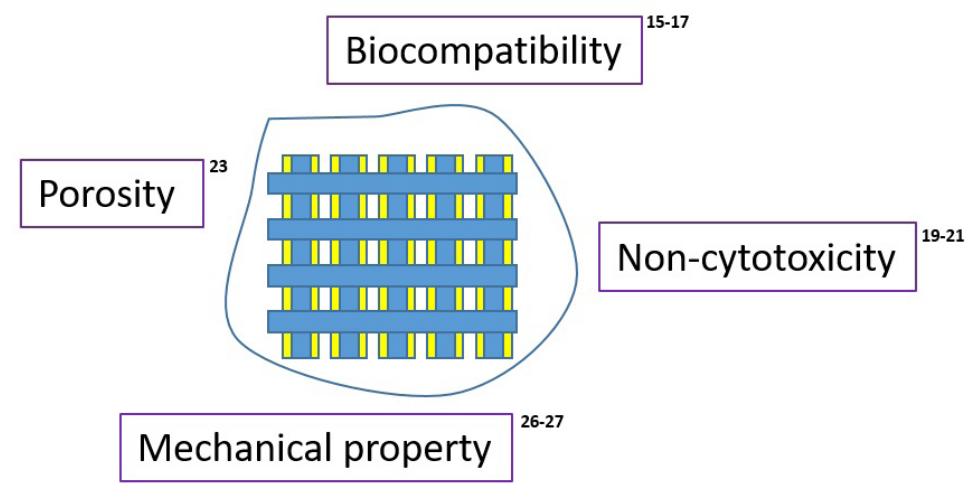

Figure 2. Main features of scaffolds. 
used to build 3D scaffolds: 3D Printing (3DP), selective laser sintering (SLS), Stereolithography (SLA), Robocasting (RC) and Fused Modeling Deposition (FDM).

Selective Laser Sintering (SLS) is a solid freeform fabrication technique, developed by Carl Deckard for his master's thesis ${ }^{43}$ at the University of Texas, patented in 1989. SLS is a technique that produces physical models through a selective solidification of a variety of fine powders. The physical aim is manufactured layer-by-layer, transforming the three-dimensional problem in a bi-dimensional one. Scaffolds are build layer-by-layer from CAD data files exported in the industry-standard exchange file format standard triangulation language (STL) ${ }^{44}$. (Figure 3).

The morphology and the particle size of the powder are well known as crucial parameters in SLS ${ }^{45,46}$. These properties have an impact on the powder bed density and on the powder flowability. The flowability of the powder is considered a critical point, because the powder must be uniformly spread at an elevated temperature and need to form layers having a thickness of about $100 \mu \mathrm{m}$. The powders used in SLS have specific granulometry and good sphericity. Commercially available SLS powders have grain size with a size distribution of $60 \mu \mathrm{m}$ and a low percentage of fine particles below $10 \mu \mathrm{m}^{47}$.

The advantages of SLS are related to fast and economical process; durable, functional, large and complex parts; small series produced in one manufacturing process; as well as sterilizable parts, high part accuracy, and material versatility ${ }^{48}$. Disadvantages may be found in parts that have rough, grainy and porous surface finish, which is not as smooth as SLA but acceptable for most of applications ${ }^{44}$.

High-quality lasers were introduced so that a partial melting of SLS has been taken over by complete melting giving rise a new development of metal laser sintering (MLS) or Selective Laser Melting (SLM). SLM is SLS done at high laser powers with an aim to achieve complete melting of metallic powders ${ }^{49,50}$. The working principle is based on fusing metal powder into a solid and melting it locally using a focused laser beam.

Polymer-based scaffolds containing bioactive bioceramics can be manufactured in which the bioceramics can serve two purposes: (a) making the scaffolds osteoconductive and (b) reinforcing the scaffolds. With this composite strategy, there are two approaches for making bioceramic-polymer composite scaffolds: (1) incorporating bioceramic particles in the scaffold through a variety of techniques and (2) coating a polymer scaffold with a thin layer of apatite through biomimetic processes ${ }^{44,51}$.

Such polymers are saturated poly(alpha-hydroxy ester), including poly(lactic acid) (PLA) and poly(glycolic acid) (PGA), as well as poly(lactic-co-glycolide) (PLGA) copolymers. PLA exists in three forms: L-PLA (PLLA), D-PLA (PDLA), and racemic mixture of D, L-PLA (PDLLA). The chemical properties of these polymers allow hydrolytic degradation through de-esterification. Once degraded, the monomeric components of each polymer are removed by natural pathways.

Poly(alpha-hydroxy ester) have been extensively studied for the fabrication of scaffolds via SLS for applications in tissue engineering (TE). Tan and collaborators ${ }^{52}$ proposed the use of a biocomposite blend comprising of PLLA and HA in SLS. Results observed from the scanning electron SEM micrographs indicate the viability of the blend used for building TE scaffolds and ascertain the capabilities of the SLS process for creating highly porous scaffolds for TE applications. Simpson and collaborators ${ }^{53}$ investigated 95/5 PLLGA for the role of a porous scaffold, using the SLS fabrication process, with powder sizes of 50-125 and 125-250 $\mu \mathrm{m}$.

For the production of objects, an algorithm is applyied in the printing system ${ }^{54}$. 3DP was considered a highly flexible process when considering the geometry, materials and desired properties. In further studies, Sachs et al. began to use metallic materials for 3DP. In addition, automation

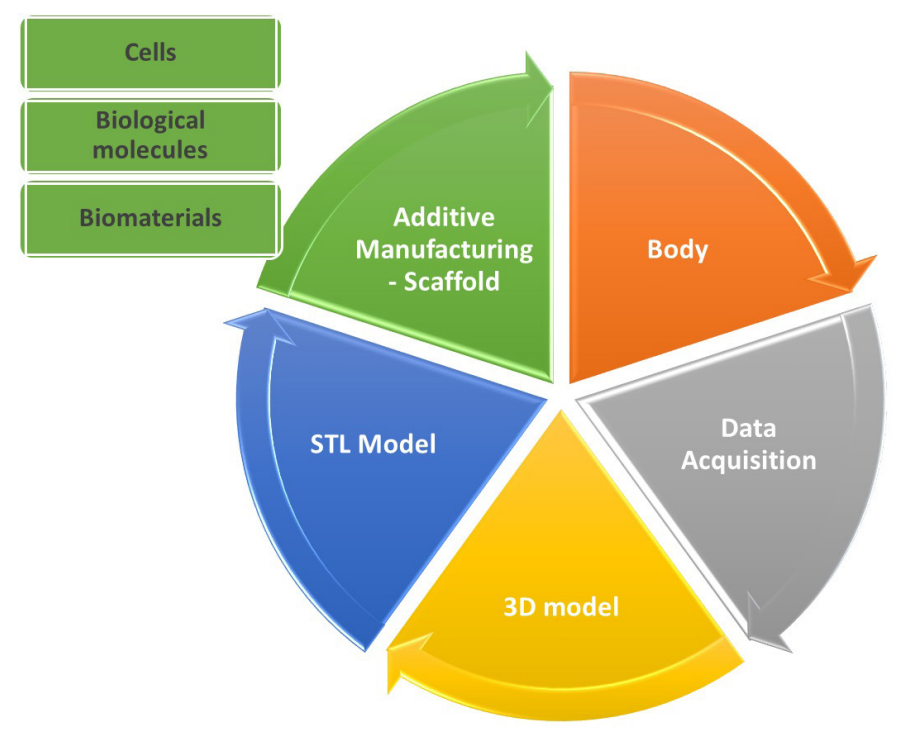

Figure 3. Schematic representation of the main steps required to produce TE scaffolds using AM technique. 
was incorporated in the production flow from design to finished product ${ }^{55}$.

In recent years, studies of 3DP were expanded, and different inorganic materials were employed as well as polymers and/or even combination thereof ${ }^{37,56,57}$. Moreover, proteins have been incorporated in their structures, where the response of the interaction of cells is enhanced with the environment formed of in these $3 \mathrm{D}$ structures ${ }^{58-60}$.

\section{Supports and Coatings for Scaffolds}

\subsection{Biocomposites}

The bone tissue by nature presents biological systems, which have the capacity to stimulate the regeneration of fracture. However, major defects and complex fractures have some limitations regenerating properly. In pursuit of to minimize these regenerative processes, biomaterials are being developed in different compositions, using materials of various natures seeking resemblance to native tissue which will regenerate, and even be replaced ${ }^{61}$.

Metallic materials such as titanium and stainless steel alloys are widely used in cases where there is an immediate need for stability and structural support of bone. These materials have excellent mechanical properties and corrosion resistance due to the presence of chromium, molybdenum and low carbon ${ }^{62-64}$.

To improve the bioactivity the surface of these metal materials, some surface treatments can be applied, such as coating, and cold plasma. Research using groups of chemicals added to the surface can increase the inducement and the growth of bone cells, beyond accelerating the regenerative process and also reducing the rejection of these materials in native tissue ${ }^{61}$.

Although metals have important properties, they have drawbacks, such as non-degradability and high stiffness, being not suitable for bone tissue regeneration. Promising results have been demonstrated with osteoconductive biomaterials, which remodel the native tissue and are capable of degrading at the same time that a new bone is obtained ${ }^{65}$.

Various types of polymers are used in bone tissue regeneration. Polymers can be divided into natural and synthetic and natural derived from a natural source such as collagen, chitosan, hyaluronic acid. Natural polymers are biocompatible and bioactive, since synthetics derived from chemical reactions, such as polifumarates, polycarbonates, can cause toxicity when in contact with the native tissue ${ }^{5}$.

\subsection{Bioceramics}

Ceramics comprises inorganic materials usually obtained after of a heat treatment at elevated temperatures ${ }^{66}$. In the filling and/or bone, replacement bioceramics are being used, while the process naturally renews functions of the native tissue. They can also be used for covering other structures in implantation as well as combined with other materials to enhance the biochemical and mechanical properties thereof ${ }^{67}$.

For about 40 years, there is a constant increase in the use of bioceramics, which actively stimulate osseointegration between the implant and native tissue ${ }^{68}$. Alumina $\left(\alpha-\mathrm{Al}_{2} \mathrm{O}_{3}\right)$ was the first bioceramic to be used due to the bioinert property ${ }^{69}$.
It presents biocompatibility and high mechanical strength, and has been used in orthopedic prostheses, replacing bones or parts of them ${ }^{70-72}$.

Beyond alumina, other ceramics have been used such as zirconia $\left(\mathrm{ZrO}_{2}\right)^{73}$, titanium dioxide $\left(\mathrm{TiO}_{2}\right)^{74}$, calcium phosphates $^{75}$ and silica glass ${ }^{76} /$ calcium phosphate $^{77}$, for instance. The use of bioceramics has been enlarged from the employment of the material to other uses, such as in the coating of metal prosthesis or in combination with polymeric materials such as collagen ${ }^{75}$, policapralactone $(\mathrm{PCL})^{78}$, among other materials.

Bioceramics induce a specific biological activity, such as hydroxyapatite $\left[\mathrm{Ca}_{10}\left(\mathrm{PO}_{4}\right)_{6}(\mathrm{OH})_{2}\right]^{79}$, tricalcium phosphate $\left[\mathrm{Ca}_{3}\left(\mathrm{PO}_{4}\right)_{2}\right]^{77}$, bioglasses ${ }^{80}$ and gypsum ${ }^{81}$.

Different methods are used for production of bioceramics, which involve different stages of synthesis ${ }^{82-86}$. A point to emphasize is the sintering at temperatures than can reach $1000{ }^{\circ} \mathrm{C}$ thus leads melting of the particles in the surface, causing them to agglomerate and form a solid dense block. This procedure results in ceramics with pores size in the micrometer $(\mu \mathrm{m})$ range including some interesting materials used in bone implants ${ }^{87,88}$.

Hulbert in $1970^{89}$ showed that pores greater than $100 \mu \mathrm{m}$ promote bone growth through the material. The pore size for cell colonization in bioceramics is around $100 \mu \mathrm{m}$. This pore size enables flow of growth factors as well as cell adhesion and proliferation, thus allowing new bone formation and developing a capillary system connected to the ceramic implant ${ }^{90}$.

To obtain ceramics with pores of this size $100 \mu \mathrm{m}$, the techniques commonly used consist in mixing a polymer or organic substance with the ceramic powder, which is subsequently eliminated during thermal processing, or wetting the powder with a volatile material that later decomposes with the release of gas forming the pores ${ }^{91}$.

$\beta$-TCP has been widely used in bone tissue engineering due to its superior oseteoconductivity, cellular adhesion, and mediation in accelerated differentiation ${ }^{92}$. Furthermore, $\beta$-TCP is more quickly degraded than crystalline hydroxyapatite ${ }^{93}$. However, $\beta$-TCP has low mechanical strength. On the other hand, biocompatible synthetic or natural polymers such as poly (L-lactide acid) (PLLA), poly (lactic-co-glycolic acid) (PLGA) and collagen have been also used as biomaterials for scaffold construction due to their biodegradability, non-biotoxic characteristics, and moderate mechanical and physical properties ${ }^{94,95}$.

\subsection{Polymers}

Ceramic scaffolds have low mechanical strength and weakness in its handling ${ }^{96}$. Polymers might be added to the ceramic to improve these characteristics. Polymers can be incorporated into these $3 \mathrm{D}$ structures, or even by coating the scaffolds in the production process, Collagen (COL), hyaluronic acid (HA) and poly(lactic acid) (PLA) are common polymers used for this purpose.

COL is the most abundant protein in the human body, corresponding to about $30 \%$ of the body's proteins. Its function is to maintain the integrity of tissue structures and give strength to various tissues and organs. Collagens differ in amino acid composition in each molecule and structural 
arrangements ${ }^{97}$. Type I collagen is the most found in blood vessels, skin, tendons and bones. Collagen on tissue is organized into fibers that are linked by hydrogen bonds, electrostatic interactions and is hydrophobic ${ }^{97}$.

HA is composed of two sugar molecules (D-glucuronic acid (known as uric acid) or DN-acetyl glucosamine), thus being considered a glycosaminoglycan ${ }^{98,99}$ and is a basic component of the ECM, which can be found in most tissues and body fluids, such as synovial fluid ${ }^{100}$. HA is a biodegradable, hydrophilic, and high molecular weight (105-107 Da) polymer, which acts as a scaffold. It also has important biological functions, such as adhesion control, mobility, differentiation and cell proliferation ${ }^{100}$.

PLA is produced from lactic acid polycondensation or by ring-opening polymerization of the lactide cyclic dimer. It was first synthesized by Carothers in $1932^{101,102}$. PLA can be degraded by non-enzymatic hydrolysis and its by-products are eliminated through normal cell metabolism ${ }^{103}$. PLA is an ideal candidate for implantable devices because it presents important characteristics such as cytocompatibility and biodegradability ${ }^{103,104}$. The regulation of PLA-based devices by the Food and Drug Administration (FDA) has raised further interest in the use of PLA in the field of tissue engineering. Tissue engineering aims to restore, sustain, or improve tissue function through the combination of three components: scaffolds, bioactive molecules, and/or cells ${ }^{1}$. PLA has a chirality of lactic acid (L- and D-lactic acid) that can be leveraged to synthesize PLA with different stereoregularities. Stereoregularity influences the physicochemical properties of the material, such as mechanical and thermal properties and degradation characteristics. Consequently, PLA has been widely used in tissue engineering applications, both as scaffolds and as drug delivery systems ${ }^{105-108}$.

The development of biomaterials that mimic the environment in which it will be implanted is in continuous research over the years. Different materials and several characteristics must be attributed in this development and the combination of materials is always a possibility, which tends to approach the native environment.

\subsection{Bone morphogenetic proteins}

Bone morphogenetic protein 2 (BMP-2) can promote healing in bone defects. This molecule stimulates the activity of osteoblasts and other cells to promote bone formation. The release of recombinant human bone morphogenetic protein 2 (rhBMP-2) to the local tissue should be controlled by delivery from osteoconductive biomaterials ${ }^{109}$.

Short BMP-2 treatment stimulated the expression of a panel of factors in hASCs that may play a role in the conditioning of the environment to facilitate bone repair in vivo. Short incubation with BMP-2 may thus be a promising treatment to enhance both osteogenic differentiation of stem cells as well as modulation of the wound environment ${ }^{110}$.

BMP-2 incorporated in gelatin sponge with calcium beta-tri-phosphate accelerated a bone rule in in vivo tests. The in vivo test was monitored for 16 weeks by radiography and historical analysis, where the results are demonstrated in a regeneration of the host tissue ${ }^{111}$.

The effect of nano-scaled surface on the adsorption and bioactivity of BMP-2 were investigated with a series of hydroxyapatite surfaces (HAp). This study indicated that the nano-scaled HAPs had obvious influences on the conformation and availability to BMPs of the adsorbed rhBMP-2, which in turn governed the bioactivity of rhBMP-2 ${ }^{112}$.

A hybrid of chitosan-xerogel membrane was combined with bone morphogenetic protein-2 (BMP-2) for enhancing bone regeneration. The ability of the hybrid membrane as a BMP-2 delivery carrier and its biological properties were examined by in vitro and in vivo tests, in comparison with the pure chitosan membrane. According to the results, the hybrid membrane exhibited higher affinity for BMP-2 than the pure chitosan membrane, thereby greatly improving its cellular responses. Moreover, the in vivo test demonstrated that the healing process was accelerated by the hybrid membrane with BMP-2 ${ }^{113}$.

Scaffold porous TCP for bone tissue engineering used a chitosan/BMP-2 coating on the surface of the scaffold, which has a good biocompatibility and osteoconductive activity. There was appreciable bone tissue formation and in growth for rhBMP-2-loaded ceramics 3 weeks after implantation. Thus, this combination could be considered an interesting approach for bone tissue engineering application ${ }^{114}$.

In a pilot study using rabbit calvarial defect model, more new bone formation was detected in rhBMP-2 impregnated groups. In another pilot study, new bone formation was increased in time-dependent manner after the graft of BCP (calcium biophosphate) and BCP-collagen composite impregnated with rhBMP-2. BCP with 30\% hydroxyapatite (HAp) showed a faster resorption rate than $\mathrm{BCP}$ with $20 \% \mathrm{HA}$. At 8 weeks, BCP-collagen composite with 30\% HAp formed more new bones than BCP-collagen with 20\% HAp and BCP-collagen composite showed more new bone formation than $\mathrm{BCP}$ without collagen. From the results of these two pilot studies, it was concluded that rhBMP-2 played positive roles in new bone formation. Moreover, BCP-collagen composite block bone showed a superior bone forming capacity on early stage and BCP-collagen with $30 \%$ HAp could be more appropriate for rhBMP-2 carrier than the others ${ }^{115}$ (Figure 4).

Dadsetan et al. evaluated the role of calcium phosphate coating and simultaneous delivery of recombinant human bone morphogenetic protein-2 (rhBMP-2) on the in vivo bone regeneration capacity of biodegradable, porous poly(propylene fumarate) (PPF) scaffolds. In vivo bone regeneration was analysed by implantation of scaffolds in a critical-sized rabbit cal- varial defect loaded with different doses of rhBMP-2. The data demonstrated that scaffolds with each of the calcium phosphate coatings were capable of sustaining rhBMP-2 release and retained an open porous structure. After 6 weeks of implantation, micro-computed tomography revealed that the rhBMP-2 dose had a significant effect on bone formation within the scaffolds and that the SBM-coated scaffolds regenerated significantly greater bone than BCP-coated scaffolds. Mechanical testing of the defects also indicated restoration of strength in the SBM and b-TCMP with rhBMP-2 delivery. Histology results demonstrated bone growth immediately adjacent to the scaffold surface, indicating good osteointegration and osteoconductivity for coated scaffolds. The results obtained in this study suggest that the coated scaffold platform demonstrated a synergistic effect between calcium phosphate coatings and rhBMP-2 delivery and may provide a promising platform for the functional restoration of large bone defects ${ }^{116}$ 


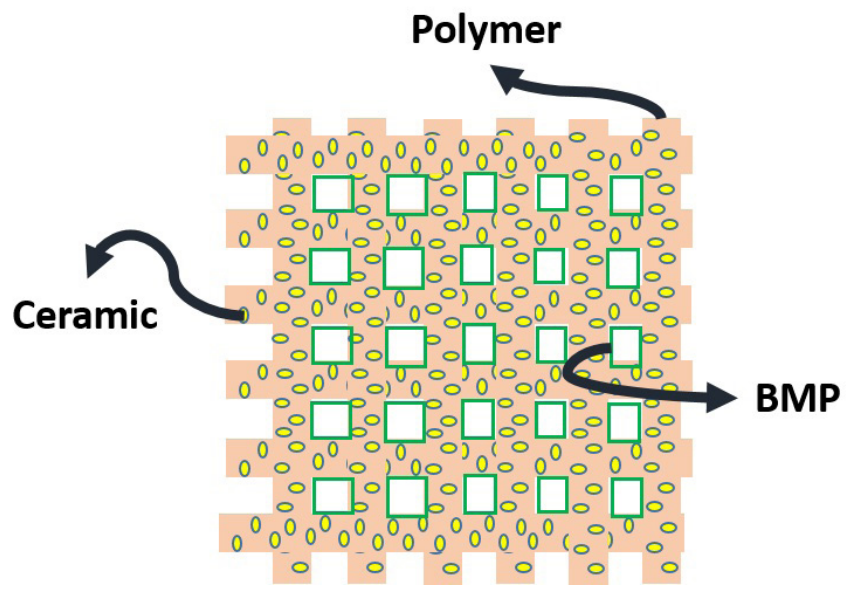

Figure 4. Scaffolds for rhBMP-2 carrier.

\section{Conclusions}

The human bone features are specific and peculiar to each bone. The bone composition consists of an inorganic part, apatite, and an organic substances, collagen fibers and cells, enabling specific production of structures. Bone regeneration occurs along with different biological pathways involved. If these processes are not in tune, they will regenerate the tissue inappropriately. Tissue engineering then arises to aggregate structures, which enable the regeneration of injured bone tissue effectively. Different techniques and materials, are in use to produce scaffolds in the regeneration of injured bone tissue. Using additive manufacturing, it is possible to customize these structures for use at the injured site. Natural and synthetic polymers are commonly employed, as well as materials that stimulate osteointegration, such as hydroxyapatite and $\beta$-TCP, eventually including growth factors. The prospect of application of this technique is very promising, as 3D-printing equipment can be easily installed in existing structures to permit customized solutions for tissue engineering.

\section{Acknowledgments}

The authors want to acknowledge the financial support from Brazilian agencies CAPES and CNPq.

\section{References}

1. Langer R, Vacanti JP. Tissue engineering. Science. 1993;260:920-6.

2. Matassi F, Nistri L, Paez DC, Innocenti M. New biomaterials for bone regeneration. Clin Cases Miner Bone Metab. 2011;8(1):21-4.

3. Fernandez-Yague MA, Abbah SA, McNamara L, Zeugolis DI, Pandit A, Biggs MJ. Biomimetic approaches in bone tissue engineering: Integrating biological and physicomechanical strategies. Adv Drug Deliv Rev. 2015;84:1-29.

4. Kang H-W, Kengla C, Lee SJ, Yoo JJ, Atala A. Rapid prototyping of biomaterials. Cambridge, UK: Woodhead Publishing Limited; 2014. p. 236-253.

5. Sionkowska A. Current research on the blends of natural and synthetic polymers as new biomaterials [Review]. Progress in Polymer Science. 2011;36(9):1254-76.

6. Hutmacher DW. Scaffolds in tissue engineering bone and cartilage. Biomaterials. 2000;21(24):2529-43.
7. Guo N, Leu MC. Additive manufacturing: Technology, applications and research needs. Front Mech Eng. 2013;8(3):215-43.

8. Barbieri D, de Bruijn JD, Luo X, Farè S, Grijpma DW, Yuan H. Controlling dynamic mechanical properties and degradation of composites for bone regeneration by means of filler content. J Mech Behav Biomed Mater. 2013;20:162-72.

9. Feyerabend F. Biomaterials for Bone Regeneration. Cambridge, UK: Woodhead Publishing Limited; 2014. pp. 225-269.

10. Clarke B. Normal bone anatomy and physiology. Clin J Am Soc Nephrol. 2008;3(Suppl. 3):1-11.

11. Bose S, Vahabzadeh S, Bandyopadhyay A. Bone tissue engineering using 3D printing. Mater Today. 2013;16(12):496-504.

12. Kokubo T, Kim H-M, Kawashita M. Novel bioactive materials with different mechanical properties. Biomaterials. 2003;24(13):2161-75.

13. Gerstenfeld LC, Cullinane DM, Barnes GL, Graves DT, Einhorn TA. Fracture healing as a post-natal developmental process: Molecular, spatial, and temporal aspects of its regulation. J Cell Biochem. 2003;88(5):873-84.

14. Deschaseaux F, Sensébé L, Heymann D. Mechanisms of bone repair and regeneration. Trends Mol Med. 2009;15(9):417-29.

15. LeGeros RZ. Calcium phosphate-based osteoinductive materials. Chem Rev. 2008;108(11):4742-53.

16. LeGeros RZ. Properties of osteoconductive biomaterials: Calcium phosphates. Clin Orthop Relat Res. 2002;(395):81-98.

17. Judas F, Palma P, Falacho R, Figueiredo H. Estrutura e dinâmica do tecido ósseo. Ceramica. 2012:51 p.

18. Griffith LG. Emerging design principles in biomaterials and scaffolds for tissue engineering. Ann NY Acad Sci. 2002;961:8395.

19. Sykaras N, Opperman LA. Bone Morphogenetic Proteins (BMPs): How do they function and what can they offer the clinician. J Oral Sci. 2003;45(2):57-73.

20. Urist MR. Bone: formation by autoinduction (Citation). Science. 1965;150(3698):893-9.

21. Bomback DA, Grauer JN. Bone morphogenetic proteins. Clin Podiatr Med Surg. 2005;18(1):2005.

22. Carreira AC, Alves GG, Zambuzzi WF, Sogayar MC, Granjeiro JM. Bone Morphogenetic Proteins: Structure, biological function and therapeutic applications. Arch Biochem Biophys. 2014;561:64-73.

23. Cheng H, Jiang W, Phillips FM, Haydon RC, Peng Y, Zhou $\mathrm{L}$, et al. Osteogenic activity of the fourteen types of human Bone Morphogenetic Proteins (BMPs). The Journal of Bone \& Joint Surgery. 2003;85(8):1544-52.

24. Torres J, Tamimi F, Alkhraisat M, Prados-frutos J, Lopez-cabarcos E, Carlos R. Bone Substitutes. Implant Dent. 2011;2011:91-108. 
25. Gothard D, Smith EL, Kanczler JM, Rashidi H, Qutachi O, Henstock J, et al. Tissue engineered bone using select growth factors: A comprehensive review of animal studies and clinical translation studies in man. Eur Cell Mater. 2014;28:166-207.

26. Lee EJ, Kasper FK, Mikos AG. Biomaterials for tissue engineering. Ann Biomed Eng. 2014;42:323-37.

27. Chaikof EL, Matthew H, Kohn J, Mikos AG, Prestwich GD, Yip CM. Biomaterials and scaffolds in reparative medicine. Ann N Y Acad Sci. 2002;961:96-105.

28. Chen Q, Zhu C, Thouas GA. Progress and challenges in biomaterials used for bone tissue engineering: bioactive glasses and elastomeric composites. Prog Biomater. 2012;1(2):1-22.

29. Fu L, Zhang J, Yang G. Present status and applications of bacterial cellulose-based materials for skin tissue repair. Carbohydr Polym. 2013;92(2):1432-42.

30. Di Martino A, Sittinger M, Risbud MV. Chitosan: A versatile biopolymer for orthopaedic tissue-engineering. Biomaterials. 2005;26(30):5983-90.

31. Farrell E, O’Brien FJ, Doyle P, Fischer J, Yannas I, Harley BA, et al. A collagen-glycosaminoglycan scaffold supports adult rat mesenchymal stem cell differentiation along osteogenic and chondrogenic routes. Tissue Eng. 2006;12(3):459-68.

32. Keogh MB, O’Brien FJ, Daly JS. A novel collagen scaffold supports human osteogenesis: Applications for bone tissue engineering. Cell Tissue Res. 2010;340(1):169-77.

33. Piaia L, Paes CQ, Porto LM. Viability of human dermal fibroblasts cultured on bacterial cellulose and Aloe vera composites. BMC Proc. 2014;8(Suppl. 4):61.

34. Yao C-H, Yeh J-Y, Chen Y-S, Li M-H, Huang C-H. Woundhealing effect of electrospun gelatin nanofibres containing Centella asiatica extract in a rat model. J Tissue Eng Regen Med. 2015

35. Hubbell JA. Materials as morphogenetic guides in tissue engineering. Curr Opin Biotechnol. 2003;14(5):551-8.

36. Khademhosseini A, Bong GC. Microscale technologies for tissue engineering. In: 2009 IEEE/NIH Life Science Systems and Applications Workshop, LiSSA; 2009 Apr 9-10; Bethesda, MD. IEEE; 2009. p. 56-7.

37. Butscher A, Bohner M, Hofmann S, Gauckler L, Müller R. Structural and material approaches to bone tissue engineering in powder-based three-dimensional printing. Acta Biomater. 2011;7(3):907-20.

38. White AA, Best SM, Kinloch IA. Hydroxyapatite-carbon nanotube composites for biomedical applications: A review. Int J Appl Ceram Technol. 2007;4(1):1-13.

39. Will J, Melcher R, Treul C, Travitzky N, Kneser U, Polykandriotis $\mathrm{E}$, et al. Porous ceramic bone scaffolds for vascularized bone tissue regeneration. J Mater Sci Mater Med. 2008;19(8):278190.

40. Oréfice R, Pereira M, Mansur H, editors. Biomateriais: fundamentos e aplicações. Rio de Janeiro: Cultura Médica; 2006.

41. Sun W, Starly B, Nam J, Darling A. Bio-CAD modeling and its applications in computer-aided tissue engineering. Comput Aided Des. 2005;37(11):1097-114.

42. Kalsoom U, Nesterenko PN, Paull B. Recent developments in 3D printable composite materials. RSC Advances. 2016;6:6035571.

43. Deckard CR. Part generation by layerwise selective sintering [M.S. thesis]. Austin: University of Texas at Austin; 1986.

44. Mazzoli A. Selective laser sintering in biomedical engineering. Med Biol Eng Comput. 2013;51(3):245-56.

45. Dupin S, Lame O, Barrès C, Charmeau JY. Microstructural origin of physical and mechanical properties of polyamide 12 processed by laser sintering. Eur Polym J. 2012;48(9):1611-21.

46. Salmoria GV, Paggi RA, Lago A, Beal VE. Microstructural and mechanical characterization of PA12/MWCNTs nanocomposite manufactured by selective laser sintering. Polym Test. 2011;30(6):611-5.

47. Drummer D, Rietzel D, Kühnlein F. Development of a characterization approach for the sintering behavior of new thermoplastics for selective laser sintering. Phys Procedia. 2010;5(Part 2):533-42.

48. Mazzoli A, Germani M, Moriconi G. Influence of different manufacturing techniques and materials on the accuracy of anatomical SFF models derived from CT data. In: Proceedings of the 3rd IASTED International Conference on Biomedical Engineering; 2005 Feb 16-18; Innsbruck, Austria. Calgary, AB: IASTED; 2005.

49. Tan KH, Chua C, Leong KF, Naing MW, Cheah CM. Fabrication and characterization of three-dimensional poly(ether-etherketone)/-hydroxyapatite biocomposite scaffolds using laser sintering. Proc Inst Mech Eng H. 2005;219(3):183-94.

50. Traini T, Mangano C, Sammons RL, Mangano F, Macchi A, Piattelli A. Direct laser metal sintering as a new approach to fabrication of an isoelastic functionally graded material for manufacture of porous titanium dental implants. Dent Mater. 2008;24(11):1525-33.

51. Bremen S, Meiners W, Diatlov A. Selective laser melting: A manufacturing technology for the future? Laser Tech J. 2012;9:33-8.

52. Tan KH, Chua CK, Leong KF, Cheah CM, Gui WS, Tan WS, et al. Selective laser sintering of biocompatible polymers for applications in tissue engineering. Biomed Mater Eng. 2005;15(1-2):113-24.

53. Simpson RL, Wiria FE, Amis AA, Chua CK, Leong KF, Hansen UN, et al. Development of a 95/5 poly(L-lactide-co-glycolide)/ hydroxylapatite and b-tricalcium phosphate scaffold as bone replacement material via selective laser sintering. J Biomed Mater Res B Appl Biomater. 2008;84(1):17-25.

54. Sachs E, Cima M, Cornie J. Three-Dimensional Printing: Rapid tooling and prototypes directly from a CAD Model. CIRP Annals. 1990;39(1):201-204.

55. Sachs E, Cima M, Cornie J, Brancazio D, Bredt J, Curodeau A, et al. Three-Dimensional Printing: The physics and implications of additive manufacturing. CIRP Annals. 1993;42(1):257-260.

56. Abdel-Halim ES, Emam HE, El-Rafie MH. Utilization of hydroxypropyl cellulose and poly(acrylic acid)-hydroxypropyl cellulose composite as thickeners for textile printing. Carbohydr Polym. 2008;74(4):938-41.

57. Tan KH, Chua CK, Leong KF, Naing MW, Cheah CM. Fabrication and characterization of three-dimensional poly(ether-etherketone)/-hydroxyapatite biocomposite scaffolds using laser sintering. Proc Inst Mech Eng H. 2005;219(3):183-94.

58. Rupcich N, Brennan JD. Coupled enzyme reaction microarrays based on pin-printing of sol-gel derived biomaterials. Anal Chim Acta. 2003;500(1-2):3-12.

59. Cai K, Dong H, Chen C, Yang L, Jandt KD, Deng L. Inkjet printing of laminin gradient to investigate endothelial cellular alignment. Colloids Surf B Biointerfaces. 2009;72(2):230-5.

60. Csucs G, Michel R, Lussi JW, Textor M, Danuser G. Microcontact printing of novel co-polymers in combination with proteins for cell-biological applications. Biomaterials. 2003;24(10):1713-20.

61. Agarwal R, García AJ. Biomaterial strategies for engineering implants for enhanced osseointegration and bone repair. Adv Drug Deliv Rev. 2015;94:53-62.

62. Albrektsson T, Hansson HA, Ivarsson B. Interface analysis of titanium and zirconium bone implants. Biomaterials. 1985;6(2):97-101

63. Holt G, Parel S, Branemark P. Osseointegrated Titanium Implants. Facial Plast Surg. 1986;3(02):113-24.

64. Kumar G, Narayan B. Osseointegrated titanium implants: Requirements for ensuring a long-lasting, direct bone-to-implant anchorage in man. In: Banaszkiewicz PA, Kader DF, editors. 
Classic papers in orthopaedics. London: Springer; 2014. p. 507-9.

65. Jäger M, Hernigou P, Zilkens C, Herten M, Fischer J, Krauspe R. Cell therapy in bone-healing disorders. Orthopade. 2010;39(4):449-62.

66. Reed JS. Principle of ceramics processing. 2nd ed. United States: John Wiley \& Sons Inc.; 1995.

67. Hench LL. Bioceramics: From concept to clinic. J Am Ceram Soc. 1991;74(7):1487-510.

68. Burchardt H, Jones H, Glowczewskie F, Rudner C, Enneking WF. Freeze-dried allogeneic segmental cortical-bone grafts in dogs. J Bone Joint Surg Am. 1978;60(8):1082-90.

69. Hulbert SF, Cooke FW. Biomedical. Mater Res. 1970;4:1.

70. Daculsi G, Hartmann DJ, Heughebaert M, Hamel L, Le Nihouannen JC. In vivo cell interactions with calcium phosphate bioceramics. J Submicrosc Cytol Pathol. 1988;20(2):379-84.

71. Bohner M. Calcium orthophosphates in medicine: From ceramics to calcium phosphate cements. Int. J. Care Injured. 2000;31:37-47.

72. Kawachi EY, Bertran CA, Dos Reis RR, Alves OL. Biocerâmicas: tendências e perspectivas de uma área interdisciplinar. Quim Nova. 2000;23(4):518-22.

73. Fielding GA, Bandyopadhyay A, Bose S. Effects of silica and zinc oxide doping on mechanical and biological properties of 3D printed tricalcium phosphate tissue engineering scaffolds. Dent Mater. 2012;28(2):113-22.

74. Cai K, Sun J, Li Q, Wang R, Li B, Zhou J. Direct-writing construction of layered meshes from nanoparticles-vaseline composite inks: rheological properties and structures. Appl Phys, A Mater Sci Process. 2011;102(2):501-7.

75. Inzana JA, Olvera D, Fuller SM, Kelly JP, Graeve OA, Schwarz EM, et al. 3D printing of composite calcium phosphate and collagen scaffolds for bone regeneration. Biomaterials. 2014;35(13):4026-34.

76. Zocca A, Gomes CM, Bernardo E, Müller R, Günster J, Colombo P. LAS glass-ceramic scaffolds by three-dimensional printing. J Eur Ceram Soc. 2013;33(9):1525-33.

77. Bergmann C, Lindner M, Zhang W, Koczur K, Kirsten A, Telle R, et al. 3D printing of bone substitute implants using calcium phosphate and bioactive glasses. J Eur Ceram Soc. 2010;30(12):2563-7.

78. Cao T, Ho K-H, Teoh S-H. Scaffold design and in vitro study of osteochondral coculture in a three-dimensional porous polycaprolactone scaffold fabricated by fused deposition modeling. Tissue Eng. 2003;9(Suppl 1):S103-12.

79. Kumar A, Nune KC, Misra RDK. Biological functionality of extracellular matrix-ornamented three-dimensional printed hydroxyapatite scaffolds. J Biomed Mater Res A. 2016;104(6),134351 .

80. Winkel A, Meszaros R, Reinsch S, Müller R, Travitzky N, Fey T, et al. Sintering of 3D-printed glass/HAp composites. J Am Ceram Soc. 2012;95(11):3387-93.

81. Pouria A, Bandegani H, Pourbaghi-Masouleh M, Hesaraki S, Alizadeh M. Physicochemical properties and cellular responses of strontium-doped gypsum biomaterials. Bioinorg Chem Appl. 2012;2012(8):976495.

82. Cox SC, Thornby JA, Gibbons GJ, Williams MA, Mallick KK. 3D printing of porous hydroxyapatite scaffolds intended for use in bone tissue engineering applications. Mater Sci Eng C. 2015;47:237-47.

83. Maas M, Hess U, Rezwan K. The contribution of rheology for designing hydroxyapatite biomaterials. Curr Opin Colloid Interface Sci. 2014;19(6):585-93.

84. Lou T, Wang X, Song G, Gu Z, Yang Z. Fabrication of PLLA/ $\beta$ TCP nanocomposite scaffolds with hierarchical porosity for bone tissue engineering. Int J Biol Macromol. 2014;69:464-70.
85. Ma XL, Dong LH, Wang X. Microstructure, mechanical property and corrosion behavior of co-continuous $\beta$ - $\mathrm{TCP} / \mathrm{MgCa}$ composite manufactured by suction casting. Mater Des. 2014;56:305-12.

86. Siqueira L, Passador FR, Costa MM, Lobo AO, Sousa E. Influence of the addition of $\beta$-TCP on the morphology, thermal properties and cell viability of poly (lactic acid) fibers obtained by electrospinning. Mater Sci Eng C. 2015;52:135-43.

87. Anthony T. Solute segregation in vacancy gradients generated by sintering and temperature changes. Acta Metall. 1969;17(5):6039.

88. Wang W, Fu Z, Wang H, Yuan R. Influence of hot pressing sintering temperature and time on microstructure and mechanical properties of TiB 2 ceramics. J Eur Ceram Soc. 2002;22:1045-9.

89. Hulbert SF, Young FA, Mathews RS, Klawitter JJ, Talbert CD, Stelling FH. Potential of ceramic materials as permanently implantable skeletal prostheses. J Biomed Mater Res. 1970

90. Hulbert SF, Young FA. No Title. J Biomed Mater Res. 1970;4:433.

91. Vakifahmetoglu C, Menapace I, Hirsch A, Biasetto L, Hauser R, Riedel R, et al. Highly porous macro- and micro-cellular ceramics from a polysilazane precursor. Ceram Int. 2009;35(8):3281-90.

92. Arahira T, Todo M. Effects of proliferation and differentiation of mesenchymal stem cells on compressive mechanical behavior of collagen $/ \beta$-TCP composite scaffold. J Mech Behav Biomed Mater. 2014;39:218-30.

93. Cao H, Kuboyama N. A biodegradable porous composite scaffold of PGA/beta-TCP for bone tissue engineering. Bone. 2010;46(2):386-95.

94. Todo M, Park SD, Takayama T, Arakawa K. Fracture micromechanisms of bioabsorbable PLLA/PCL polymer blends. Eng Fract Mech. 2007;74(12):1872-83.

95. Arahira T, Maruta M, Matsuya S, Todo M. Development and characterization of a novel porous $\beta$-TCP scaffold with a threedimensional PLLA network structure for use in bone tissue engineering. Mater Lett. 2015;152:148-50.

96. Brunello G, Sivolella S, Meneghello R, Ferroni L, Gardin C, Piattelli A, et al. Powder-based 3D printing for bone tissue engineering. Biotechnol Adv. 2016

97. Söderhäll C, Marenholz I, Kerscher T, Rüschendorf F, EsparzaGordillo J, Worm M, et al. Variants in a novel epidermal collagen gene (COL29A1) are associated with atopic dermatitis. PLoS Biol. 2007;5(9):1952-61.

98. Collins MN, Birkinshaw C. Hyaluronic acid based scaffolds for tissue engineering: A review. Carbohydr Polym. 2013;92(2):126279.

99. Wight TN, Evanko S, Kolodgie F, Farb A, Virmani R. Chemistry and biology of hyaluronan. In: Garg HG, Hales CA, editors. New York: Elsevier; 2004. p. 307-321.

100.Fakhari A, Berkland C. Applications and emerging trends of hyaluronic acid in tissue engineering, as a dermal filler and in osteoarthritis treatment. Acta Biomater. 2013;9(7):7081-92.

101.Castro-Aguirre E, Iñiguez-Franco F, Samsudin H, Fang X, Auras R. Poly(lactic acid)-Mass production, processing, industrial applications, and end of life. Adv Drug Deliv Rev. 2016;107:333-366.

102.Kulkarni RK, Moore EG, Hegyeli AF, Leonard F. Biodegradable poly(lactic acid) polymers. J Biomed Mater Res. 1971;5(3):16981.

103.Lasprilla AJR, Martinez GAR, Lunelli BH, Jardini AL, Filho RM. Poly-lactic acid synthesis for application in biomedical devices: A review. Biotechnol Adv. 2012;30(1):321-8.

104.Lovald ST, Khraishi T, Wagner J, Baack B. Mechanical design optimization of bioabsorbable fixation devices for bone fractures. J Craniofac Surg. 2009;20(2):389-98.

105. Savioli Lopes M, Jardini AL, Maciel Filho R. Poly (lactic acid) production for tissue engineering applications. Procedia Eng. 2012;42:1402-13.

106. Bigg DM. Polylactide copolymers: effect of copolymer ratio and end capping on their properties. Adv Polym Technol. 2005;24(2):69-82. 
107.Park J, Lakes RS. Biomaterials: An introduction. 3rd ed. New York: Springer; 2007. 561 p.

108. Santoro M, Shah SR, Walker JL, Mikos AG. Poly(lactic acid) nanofibrous scaffolds for tissue engineering. Adv Drug Deliv Rev. 2016;107:206-12.

109. Mao L. Assessement of bone regeneration in a rat femur defect model following recombinant human bone morphogenetic protein 2 delivery from keratin hydrogels with tunable rates of degradation: micro-ct analysis and histology [dissertation]. Miami, Florida: Miami University; 2016.

110. Overman JR, Helder MN, ten Bruggenkate CM, Schulten EAJM, Klein-Nulend J, Bakker AD. Growth factor gene expression profiles of bone morphogenetic protein-2-treated human adipose stem cells seeded on calcium phosphate scaffolds in vitro. Biochimie. 2013;95(12):2304-13.

111. Tsuzuki N, Otsuka K, Seo J, Yamada K, Haneda S, Furuoka $\mathrm{H}$, et al. In vivo osteoinductivity of gelatin $\beta$-tri-calcium phosphate sponge and bone morphogenetic protein- 2 on an equine third metacarpal bone defect. Res Vet Sci. 2012;93(2):1021-5.
112. Huang B, Yuan Y, Ding S, Li J, Ren J, Feng B, et al. Nanostructured hydroxyapatite surfaces-mediated adsorption alters recognition of BMP receptor IA and bioactivity of bone morphogenetic protein-2. Acta Biomater. 2015;27:275-85.

113.Lee EJ, Kim HE. Accelerated bony defect healing by chitosan/ silica hybrid membrane with localized bone morphogenetic protein-2 delivery. Mater Sci Eng C. 2016;59:339-45.

114. Abarrategi A, Moreno-Vicente C, Ramos V, Aranaz I, Sanz Casado JVP-LJL. Improvement of porous $\beta$-TCP scaffolds with rhBMP-2 chitosan carrier film for bone tissue application. Tissue Eng Part A. 2008;14(8):1305-19.

115. Yun P-Y, Kim Y-K, Jeong K-I, Park J-C, Choi Y-J. Influence of bone morphogenetic protein and proportion of hydroxyapatite on new bone formation in biphasic calcium phosphate graft: two pilot studies in animal bony defect model. J Craniomaxillofac Surg. 2014;42(8):1909-17.

116. Dadsetan M, Guda T, Runge MB, Mijares D, Legeros RZ, Legeros JP, et al. Effect of calcium phosphate coating and rhBMP-2 on bone regeneration in rabbit calvaria using poly(propylene fumarate) scaffolds. Acta Biomater. 2015;18:9-20. 